TITLE:

\title{
Facebook's Libra is far from broad acceptance as a world currency
}

$\operatorname{AUTHOR}(\mathrm{S})$ :

Iwashita, Naoyuki

\section{CITATION:}

Iwashita, Naoyuki. Facebook's Libra is far from broad acceptance as a world currency. Evolutionary and Institutional Economics Review 2021, 18: 335-339

ISSUE DATE:

2021-04

URL:

http://hdl.handle.net/2433/264948

\section{RIGHT:}

This is a post-peer-review, pre-copyedit version of an article published in Evolutionary and Institutional Economics Review. The final authenticated version is available online at: https://doi.org/10.1007/s40844-020-00165-2.; The full-text file will be made open to the public on 7 March 2021 in accordance with publisher's 'Terms and Conditions for SelfArchiving'.; This is not the published version. Please cite only the published version. この論文は出版社版でありません

。引用の際には出版社版をご確認ご利用ください。 


\title{
Facebook's Libra is far from broad acceptance worldwide
}

\author{
Naoyuki Iwashita ${ }^{1}$ \\ Kyoto University School of Government
}

October $11^{\text {th }}, 2019$

\begin{abstract}
- Facebook's Libra intends to provide a financial infrastructure for the people living in the developing countries in which financial inclusion rates still fall low.

- Libra plans to stabilize the market by holding legal currencies as collateral. However, markets determine prices, and there is no guarantee that the prices can be controlled as intended.

- As long as a central authority holds legal currencies as collateral and issues the Libra, it cannot be a decentralized structure like bitcoin. Libra plans to move to a permissionless blockchain within five years, but no concrete steps have been proposed yet.
\end{abstract}

Facebook's Libra proposal is receiving worldwide attention. According to a published white paper, Libra is a cryptocurrency issued using the blockchain technology to provide a financial infrastructure for billions of people around the world.

In developed countries, including Japan, it is common for people to open bank accounts if they wish to do so. The proportion of bank account holders in the adult population (financial inclusion rate) has always exceeded $80 \%$ in developed countries. However, when you look around the world, until only about ten years ago, most non-developed countries had financial inclusion rates below $50 \%$. Thus, the majority of people were unable to reap the benefits of financial services.

However, over the past ten years, electronic financial services have widely spread around the world because of information technology innovations, such as smartphones. Cashless payments have now become common in many emerging countries, not just in developed countries. Moreover, access to financial services, such as person-to-person remittances and asset management, has dramatically improved. The financial inclusion ratio of emerging countries has rapidly risen over six years since 2011. According to the statistics, in 2017, China, India, Kenya, and other emerging countries achieved financial inclusion rates of approximately $80 \%$, similar to those of developed countries.

\footnotetext{
1 iwashita.naoyuki.7e@kyoto-u.ac.jp
} 
Meanwhile, many developing countries have not benefited from such information technology innovations. In many of the developing countries of Africa and Latin America, financial inclusion rates still fall short of $50 \%$ because of the lack of a national infrastructure for electronic payment services. Hundreds of millions of people in those countries are still forced to use currencies such as notes and coins and rely on manual transport for shopping, saving, and transferring money to their families.

Libra envisions people living in these countries. Mobile devices are extensively used among them. Even if the nation's payment service infrastructure is not yet in place, the ability to make electronic payments, transfer money, and manage assets from mobile terminals connected to the Internet provides significant convenience to the people.

Financial Inclusion Rates in 2011 and 2017 (Source: World Bank)
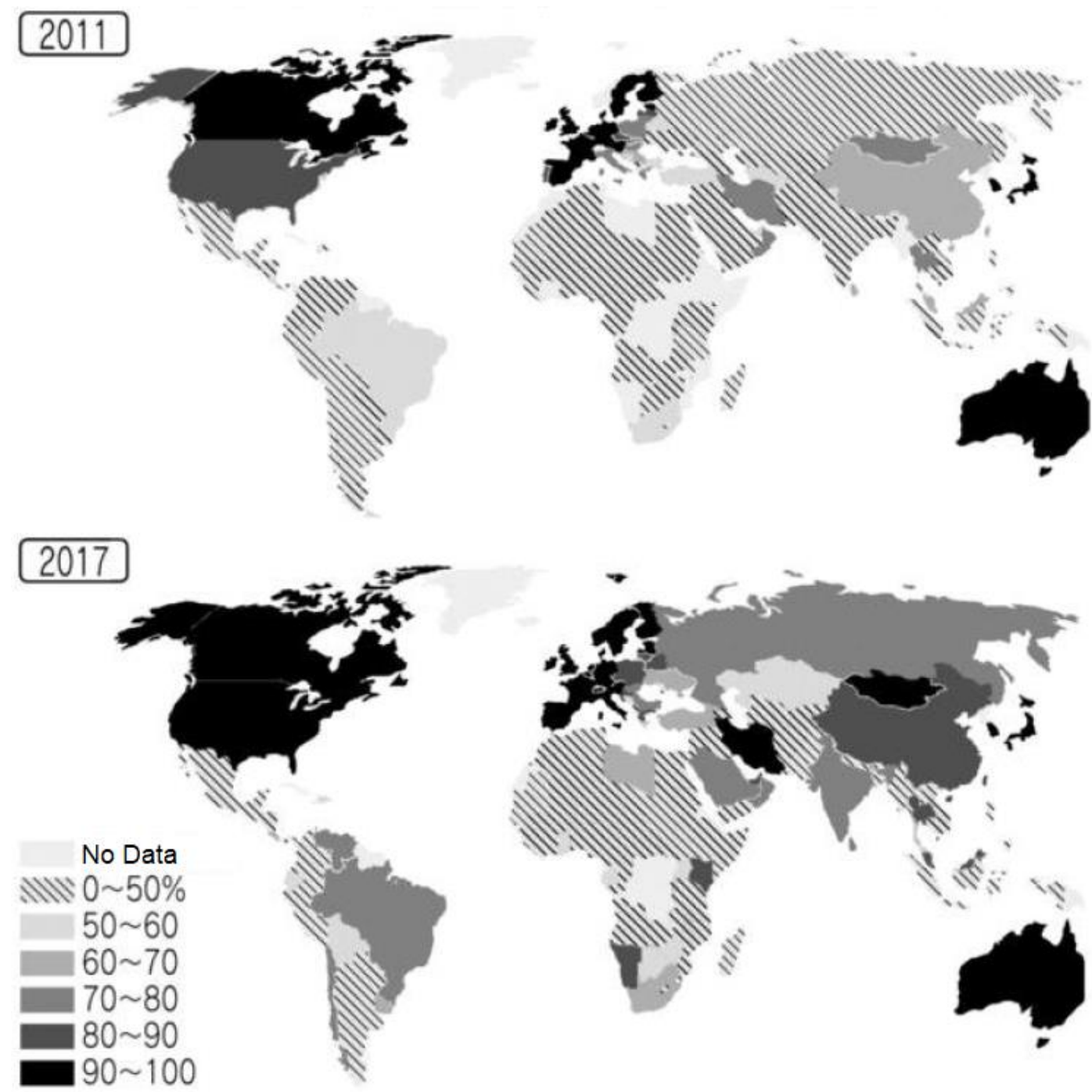
Given this, Libra sounds like an excellent proposal. However, in congressional hearings, Mr. David Marcus from Facebook faced a flurry of worrying and criticism. What is causing this criticism?

First, there is a question of whether or not Libra will be a convenient currency used around the world. Bitcoin and other crypto-assets already exist. Currently, crypto-assets worth several 10 trillion yen are issued and can be transferred over the Internet across borders, thus making it possible to buy and sell cryptoassets even in countries where the infrastructure for domestic settlement systems is not yet in place. However, they are rarely used for daily shopping because of the market's volatility. They were called "virtual currency," however, since they did not function as a currency, their name has been changed at the Buenos-Aires summit, and Japan has revised its law to call them "crypto-asset."

Libra plans to stabilize the market by establishing an organization that holds a certain percentage of legal currency as collateral. However, markets determine prices, and there is no guarantee that the prices can be controlled as intended. In fact, the price of bitcoin has skyrocketed and plummeted just because of people's expectations, even if there is no legal currency to back it up. Unsurprisingly, Libra, which is backed by a certain percentage of the legal currency, will soar more than bitcoin. In that case, the holder would temporarily gain profits, but the market would become unstable, and the currency would become useless.

Second, Libra could become a crime or an accident, as has been the case with a series of illegal leaks of crypto-assets from exchanges. Who would be responsible for regulating, supervising, and auditing Libra, which is used around the world and freely exchanged across borders? In the event of a crime or an accident, how should it be investigated? How should it be brought to justice under the laws of the respective country? If they remain unknown, they cannot be used safely.

Third, Libra could be used for money laundering for tax evasion, arms, and drug trafficking, or for financing terrorism. Bitcoin has also reportedly been used for international remittances in this area. If Libra can deliver more reliability and ease of use compared to bitcoin, it will be more convenient not only for users around the world but also for potential criminals. To prevent the abuse of Libra, Libra operators must introduce measures equivalent to the anti-money laundering measures currently followed by banks; however, it is difficult to implement the same in reality.

From a financial regulatory point of view, even if Libra has some benefits, it will be difficult for regulators to accept the plan unless adequate measures are taken against illicit transactions.

Gratefully, the Internet has allowed information to be exchanged and shared across borders; however, border barriers still exist for currency exchange. This is not to protect the existing financial industry, but to 
prevent the evils caused due to illegal international remittances. We need to accept it under the current national framework and the regulations of each country and the policy objectives of crime prevention and consumer protection.

Except for Facebook, three of the giant platform companies, called GAFA, are already managing their namesake payment services in major countries around the world. However, they are denominated in the legal currency of each country and have been built as a domestic retail settlement method in accordance with the regulations of each country. If Facebook wants to do more for people in developing countries, it would be more realistic and less problematic from a financial regulatory point of view to focus on developing country-specific retail payment solutions, just like the other three companies.

From a technical point of view, the currently proposed Libra uses the permissioned blockchain used by financial institutions for demonstration experiments, rather than the permissionless blockchain used by bitcoin and others. As long as a central authority holds legal currencies as collateral and issues the Libra, it cannot be a decentralized structure like bitcoin[1]. While Libra's system avoids the enormous energy wastage of bitcoin mining, it does not exclude the possibility that a particular central agency will dominate the network.

Bitcoin is believed to have been largely accepted by people in countries with different political regimes across borders because of its lack of a specific central authority, which is not the case with the current Libra. For example, nullifying a specific transaction in Libra if the central organization decides to do so, in cases such as asset freeze in connection with international disputes, is technically possible. Libra has said it plans to move to a permissionless blockchain within five years, but that transition is technically very difficult, and no concrete steps exist in the transition plan document[2][3][4]. From this technical point of view, it would be difficult for Libra to be realized and widely accepted from all over the world in accordance with the current concept.

\section{References}

[1] S. Nakamoto, "Bitcoin: A Peer-to-Peer Electronic Cash System," 2008. https://bitcoin.org/bitcoin.pdf

[2] The Libra Association, “An Introduction to Libra," 2019.

https://libra.org/en-us/whitepaper.

[3] Z. Amsden et al., "The Libra Blockchain," 2019.

https://developers.libra.org/docs/the-libra-blockchainpaper.

[4] S. Bano et al., "Moving toward permissionless consensus," 2019.

https://libra.org/permissionless-blockchain. 